\title{
Factors Associated with Antenatal Depression in Palestinian Refugee Camps in West Bank /Palestine: Cross Sectional Study
}

\author{
Mariam Al-Tell ${ }^{1 *}$ and Alaa Abu Iznait ${ }^{2}$ \\ ${ }^{1}$ Community Health, An-Najah National University, Palestine \\ ${ }^{2}$ UNRWA Clinic, Palestine
}

Submission: December 12, 2019; Published: December 17, 2019

*Corresponding author: Mariam Al-Tell, Community Health, An-Najah National University, Palestine

\begin{abstract}
Introduction: Pregnancy is a natural period of women life cycle; it is also a time of physical and psychological changes that have to include pleasure, joy and hope feelings to women herself and her family. However, it can be a stressful period that facilitate the increasing of depression rate

Aim of Study: the study aimed at finding out the prevalence rate of depression among Palestinian pregnant women and the related associated factors during the period of study

Method: A quantitative cross-sectional study design was used to achieve the aim of the study. Data was collected from 327 pregnant women during the period of April to June 2016 from the Antenatal clinic in the 9 refugee camps distributed in the North, middle and southern regions of the West Bank. Self-administrative was used, it consisted of questions about demographic data, exposure to violence during pregnancy, availability of support person. to assess the depression level, depression scale from the patient health questionnaire -9 (PHQ-9) was used

Results: the findings of study indicated the rate of depression among pregnant women was high. About 59.5\% of pregnant women reported different level of depression, $2.1 \% 7$ classified to have severe level of depression while 34\% (111) classified having mild level of depression. The result also revealed that $57.1 \%$ of those who have a moderate degree of depression were exposed to sexual violence by their husband.

Conclusion and Recommendation: Age group, exposure to violence, availability of support person and the number of pregnancies increasing are factors increasing the probability to develop depression during pregnancy. Findings suggest the need for detection of depression symptoms during the antenatal visits, and to provide support and protection for women. There is also a need for further study to be conducted in governmental clinics and using the qualitative approach.
\end{abstract}

Keywords: Depression; Pregnancy; Violence; Trimester; Antenata

\section{Introduction}

Depression was defined by WHO, 2017 as "a common mental disorder that presents with depressed mood, loss of interest or pleasure, decreased energy, feelings of guilt or low self-worth, disturbed sleep or appetite, and poor concentration" [1]. Globally depression is one of the most burdensome diseases [1], it is considered the leading cause of disability among both genders, but its burden is $50 \%$ higher among females than male [2]. Its rate is of two- layered among women (20-25\%) than in men (7-12\%) [3], still, it is not known the reason behind this disparity but it might be due to the social roles differences that carried out by men and women [3]. It is estimated to be higher among women at childbearing age than any other time $[3,4]$ as women are at risk of developing it during adolescence, before menstruation, during pregnancy, after delivery, and at premenopausal age [3]. The incidence rate of depression during pregnancy ranges from 6-25\% [3] but it alters according to the trimester of pregnancy. It was estimated that the occurrence rate during the first trimester by $7.4 \%(2.2-12.6 \%)$ women, in the second trimester by $12.8 \%$ (10.7$14.8 \%)$, and by $12.0 \%$ (7.4-16.7\%) during the third trimester [3] In addition, the Prevalence of prenatal depression is higher in low to middle income $19-25 \%$ countries than in high-income countries $7-15 \%$ [4], it ranged in high-income countries from $7-20 \%$ while it reached more in low-income countries [5]. The risk factors of depression involve postpartum depression after previous deliveries, the occurrence of depression in the family, a pregnancy at a young age, an unplanned pregnancy, a previous miscarriage, a lack of or limited support of the environment and partner, conflicts with the father of the child, a low level of education, lack of work, and substance abuse [3]. Other factors of the antenatal depression 


\section{Global Journal of Reproductive Medicine}

include limited emotional support, significant stress, weight, and the gender of the infant, stress caused by infant abnormalities, apprehension about labor-related pain, maternal substance use and trauma $[6,7]$.

Antenatal depression increases the risk of pre-eclampsia or hypertension, operative deliveries, spontaneous preterm births, anemia, diabetes, postnatal depression, and suicidal ideation $[6,7]$. The risk on infants increase the slower fetal activity, low birth weight, afterward admission to the neonatal care unit and sudden death [7] Changes that occur during pregnancy as hormonal changes, physical body changes might alter the psychological status of the women, in addition, there are other distressing concerns as fetus sex especially among our Palestinian culture, the presence of an abnormality in the fetus, and the labor pain. Estimating the rate of antenatal depression and identifying the associated factors might contribute to providing depression screening tools that will help health care practitioners to early detect the sign and symptom of depression during pregnancy and so to prevent unfavorable prognosis. It will also help the ministry of health to develop policies to ensure the holistic care of women considering psychological and physical health during pregnancy. Moreover, at the knowledge of researcher, the factors related to depression among Palestinian women has not been studied. This study aimed at estimating out the rate of depression among
Palestinian pregnant women and to find out the related associated factors, it hypothesized that:

a) There is a relationship between depression and number of gravidities

b) There is a relationship between the availability of a supportive person depression

c) There is a relationship between exposure to violence by husband and depression

\section{Methodology}

Analytical cross-sectional design was conducted at all UNRWA Primary Health Care(PHC) centers in three major cities (Nablus, Ramallah, and Hebron), which represent the north; middle and south of West Bank respectively and included the following nine camps (Old Askar, New Askar, Balata, Camp No.1, Al Amari, Al Jalazone, Deer Ammar, Al Fawar, and Al Aroub camp). The total number of pregnant women who registered at UNRWA antenatal clinics during 2016 estimated to be 2166 and distributed in the camps as per Table 1 . The sample size was determined to be 327 according to the following equation with (95\%) confidence level and (5\%) margin error and (50\%) response distribution.

$$
n=X 2 * N * P-(1-P) /(M E 2 *(N-1))+(X 2 * P *(1-P))
$$

Table 1: population and sample size of registered pregnant in Ante-Natal camp clinics.

\begin{tabular}{|c|c|c|c|c|c|c|c|c|c|c|}
\hline Area & \multicolumn{4}{|c|}{ Nablus } & \multicolumn{3}{|c|}{ Ramallah } & \multicolumn{2}{|c|}{ Hebron } & \multirow[t]{2}{*}{ Total } \\
\hline \multirow{2}{*}{$\begin{array}{c}\text { Population / } \\
\text { Camps }\end{array}$} & New Asker & Old Asker & Camp No1 & Balata Camp & Alamari & Aljalazone & $\begin{array}{c}\text { Deer } \\
\text { Ammar }\end{array}$ & Al Aruba & Al Fawar & \\
\hline & 87 & 267 & 268 & 476 & 345 & 246 & 52 & 209 & 216 & 2166 \\
\hline \multirow[t]{2}{*}{ S size } & 13 & 40 & 40.5 & 72 & 52 & 37 & 8 & 31.5 & 33 & 327 \\
\hline & \multicolumn{4}{|c|}{165.5} & \multicolumn{3}{|c|}{97} & \multicolumn{2}{|c|}{64.5} & 327 \\
\hline
\end{tabular}

The stratified sampling method was applied utilizing the proportional method to calculate the sample size for each city and camp as per table [1] to ensure that all camps are represented in the study. Every other woman was selected from each clinic, including those who have spontaneous pregnancy and excluding those who previously were diagnosed with depression or any other mental illness. The Data was collected using a self-administered questionnaire which included demographic data questions and few questions to assess the exposure to violence during pregnancy. To assess the symptoms of depression the 9-item depression module PHQ-9 was used, it is the 9-item depression module from the full patient health questionnaire PHQ [8]. To ensure the validity and reliability of the tool the Arabic version of the scale was used, it was reviewed by experts in mental health, and a pilot study was conducted on $(5 \%)$ of the sample size which was excluded from sample size and Cronbach Alpha for the depression scale (0.83). The study was approved by the UNRWA head office in Jerusalem, and the Institutional Review Board (IRB) from A Najah National
University. In addition, a consent form from every woman was signed to ensure her agreement in participating.

\section{Field Work}

Several recurrent visits were held between the ends of April to end of June 2016 on a daily base. In the first visit, a list of registered pregnant women in the ANC in each camp was prepared by taking the file number of pregnant women. The list was used to select every other woman and to avoid the duplication of the same women in the sample. In the following visits, the data collection tool was distributed and reviewed on the same day. The visits were repeated until the number from each camp was reached. The study wasn't with no limitations, the distribution of the refugee antenatal clinic all over the West Bank, and the transportation difficulties with the area needed doubled efforts, money and time. The cultural perspectives has its effect during collecting the data especially when assessing the exposure to violence. The Statistical Package for Social Science (SPSS) version 20 was used to analyze 


\section{Global Journal of Reproductive Medicine}

the data. The participants' responses were converted to the 4-Likert scale by recoding the answers to numeric values; three points were given for 'nearly every day' answers, two points were given for 'more than half the days', one point was given for 'several days', and zero points were given for 'not at all' answers. Then depression severity was calculated and classified accordingly to five categories from no depression (0-4) to severe depression (2027) [8]. Mean of the depression was calculated and the Chi-square test was used to test the hypothesis (depression degree, and the age of pregnant women, gravidity, availability of supportive person, and exposure to violence)

\section{Results}

Table 2: Distribution of percentage of pregnant women regarding to their demographic data.

\begin{tabular}{|c|c|c|c|}
\hline Variable & Category & No. & $\%$ \\
\hline \multirow{6}{*}{ Age } & $(16-21)$ & 58 & 17.8 \\
\hline & $(22-27)$ & 146 & 44.8 \\
\hline & $(28-33)$ & 84 & 25.8 \\
\hline & $(34-39)$ & 32 & 9.8 \\
\hline & $(\geq 40)$ & 6 & 1.8 \\
\hline & Total & 326 & 100 \\
\hline \multirow{3}{*}{ Marital status } & Married & 324 & 99.4 \\
\hline & Widow & 2 & 0.6 \\
\hline & Total & 326 & 100 \\
\hline \multirow{4}{*}{ Place of Residency } & City & 103 & 31.6 \\
\hline & Village & 49 & 15 \\
\hline & Camp & 174 & 53.4 \\
\hline & Total & 326 & 100 \\
\hline \multirow{6}{*}{ Number of gravidities } & One & 98 & 30.1 \\
\hline & Two & 79 & 24.2 \\
\hline & Three & 58 & 17.8 \\
\hline & Four & 42 & 12.9 \\
\hline & $>4$ & 49 & 15 \\
\hline & Total & 326 & 100 \\
\hline \multirow{6}{*}{ Availability of supporting person } & No one & 26 & 8 \\
\hline & Mother & 134 & 41.1 \\
\hline & Husband & 132 & 40.5 \\
\hline & Friend & 15 & 4.6 \\
\hline & Another & 19 & 5.8 \\
\hline & Total & 326 & 100 \\
\hline
\end{tabular}

A. Table 2 indicated that $53 \%$ of pregnant women live in a camp, $99.4 \%$ of them are married, and $40.5 \%$ of them considered their husband as a supporting person.

Table 3: distribution the percentage of pregnant women regarding to exposure to violence by husband.

\begin{tabular}{|c|c|c|c|c|}
\hline \multirow{2}{*}{ Type of Violence } & \multicolumn{2}{|c|}{ Yes } & \multicolumn{2}{|c|}{ No } \\
\hline & No. & $\%$ & No. & $\%$ \\
\hline Emotional violence & 56 & 17.2 & 270 & 82.8 \\
\hline Physical violence & 21 & 6.4 & 305 & 93.6 \\
\hline Sexual abuse & 7 & 2.1 & 319 & 97.9 \\
\hline $\begin{array}{l}\text { Are you afraid of your husband or } \\
\text { any one }\end{array}$ & 17 & 5.2 & 309 & 94.8 \\
\hline
\end{tabular}

B. Table 3 reported that $17.2 \%$ of pregnant women admitted that they had been exposed to emotional violence and $6.4 \%$ were exposed to physical violence during their current pregnancy.

Table 4: Distribution of percentage of pregnant women regarding to degrees of depression they have.

\begin{tabular}{|c|c|c|}
\hline Degree of Depression & No. & \% \\
\hline No - minimal depression & 132 & 40.5 \\
\hline Mild & 111 & 34 \\
\hline Moderate & 56 & 17.2 \\
\hline Moderate to Severe & 20 & 6.1 \\
\hline Severe & 7 & 2.1 \\
\hline Total & 326 & 100 \\
\hline
\end{tabular}

C. Table 4 indicated that $59.5 \%$ of pregnant women classified having various degrees of depression as follows: $34 \%$ $17.2 \%$ and $2.1 \%$ have a mild, moderate and severe degree of depression respectively.

D. Table 5 revealed that $53.4 \%$ of pregnant women in the age group 16-21 were classified to have no depression and $1.7 \%$ of them have a severe degree of depression. 8.6\%, 19.9\%, 14.3\%, $25 \%$ and $33.3 \%$ of those who classified to have a moderate degree of depression was from the age groups (16-21),(22-27), (2833 ), (34-39), and $\geq 40$ years old respectively with statistically significant differences (P-value, 0.017).

E. Table 6 showed that $5.2 \%$ and $12.1 \%$ of three gravidity pregnant women had a severe degree and moderate to severe degree of depression respectively. It also revealed that $33.7 \%$, $35.4 \%, 34.5 \%, 31 \%$ and 34.7 of those who classified having a mild degree of depression were having one, 2, 3,4 and more than one children respectively with statistically significant differences between the degree of depression and number of children (P-value0,.022).

F. Table 7 reported that $40.5 \%$ of pregnant women classified to have no degree of depression, $40.3 \%$ and $45.5 \%$ 


\section{Global Journal of Reproductive Medicine}

of them reported that their support person was their mother and their hatbands respectively. $2.1 \%$ of pregnant women were classified as having a severe degree of depression, $7.7 \%$ and $5.3 \%$ of them considered themselves having no supportive person or having another relative other than a mother or husband as a supportive person without statistically significant differences (P-value 0.070).

G. Table 8 indicated that $35.7 \%$ of pregnant women who had no degree of depression reported exposure to emotional violence from their husband, and $32.1 \%$ of them who had a mild degree of depression reported having been exposed to violence from their husband without significant differences (P-value=0.563). It also indicated that $4.8 \%$ of pregnant women who had severe depression were also exposed to physical violence from their husband, and $28.6 \%, 28.6 \%$ of those who have a moderate and mild degree of depression respectively have been exposed to physical violence by their husband without significant differences (P-value, 0.404). The table also indicated that that $57.1 \%$ of those who have a moderate degree of depression were exposed to sexual violence by their husband while $2.2 \%$ of those who had severe depression have not been exposed to sexual violence with no significant differences between them (P-value 0.074).

Table 5: Distribution of percentage of pregnant women according to the degree of depression in relation to age.

\begin{tabular}{|c|c|c|c|c|c|c|c|c|c|c|c|c|}
\hline \multirow[b]{3}{*}{ Degree of Depression } & \multicolumn{12}{|c|}{ Age Groups } \\
\hline & \multicolumn{2}{|c|}{$(16-21)$} & \multicolumn{2}{|c|}{$(22-27)$} & \multicolumn{2}{|c|}{$(28-33)$} & \multicolumn{2}{|c|}{ (34-39) } & \multicolumn{2}{|c|}{$\geq 40$} & \multicolumn{2}{|c|}{ Total } \\
\hline & No. & $\%$ & No. & $\%$ & No. & $\%$ & No. & $\%$ & No. & $\%$ & No. & $\%$ \\
\hline None & 31 & 53.4 & 55 & 37.7 & 33 & 39.3 & 11 & 34.4 & 2 & 33.3 & 132 & 40.5 \\
\hline Mild & 21 & 36.2 & 49 & 33.6 & 30 & 35.7 & 10 & 31.3 & 1 & 16.7 & 111 & 34 \\
\hline Moderate & 5 & 8.6 & 29 & 19.9 & 12 & 14.3 & 8 & 25 & 2 & 33.3 & 56 & 17.2 \\
\hline Moderate to Severe & 0 & 0 & 10 & 6.8 & 7 & 8.3 & 2 & 6.3 & 1 & 16.7 & 20 & 6.1 \\
\hline Severe & 1 & 1.7 & 3 & 2.1 & 2 & 2.4 & 1 & 3.1 & 0 & - & 7 & 2.1 \\
\hline Total & 58 & 17.8 & 146 & 44.8 & 84 & 25.8 & 32 & 9.8 & 6 & 1.8 & 326 & 100 \\
\hline & & & i-Squa & 730; P & ue $=0$ & & & & & & & \\
\hline
\end{tabular}

Table 6: Distribution of percentage of pregnant women according to the degree of depression in relation to number of gravidities.

\begin{tabular}{|c|c|c|c|c|c|c|c|c|c|c|c|c|}
\hline \multirow{3}{*}{ Degree of Depression } & \multicolumn{12}{|c|}{ Number of Gravidity } \\
\hline & \multicolumn{2}{|c|}{ One } & \multicolumn{2}{|c|}{ Two } & \multicolumn{2}{|c|}{ Three } & \multicolumn{2}{|c|}{ Four } & \multicolumn{2}{|c|}{$>4$} & \multicolumn{2}{|c|}{ Total } \\
\hline & No. & $\%$ & No. & $\%$ & No. & $\%$ & No. & $\%$ & No. & $\%$ & No. & $\%$ \\
\hline None & 46 & 46.9 & 31 & 39.2 & 22 & 37.9 & 19 & 45.2 & 14 & 28.6 & 132 & 40.5 \\
\hline Mild & 33 & 33.7 & 28 & 35.4 & 20 & 34.5 & 13 & 31 & 17 & 34.7 & 111 & 34 \\
\hline Moderate & 15 & 15.3 & 15 & 19 & 6 & 10.3 & 7 & 16.7 & 13 & 26.5 & 56 & 17.2 \\
\hline Moderate to Severe & 4 & 4.1 & 3 & 3.8 & 7 & 12.1 & 2 & 4.8 & 4 & 8.2 & 20 & 6.1 \\
\hline Severe & 0 & 0 & 2 & 2.5 & 3 & 5.2 & 1 & 2.4 & 1 & 2 & 7 & 2.1 \\
\hline Total & 98 & 30 & 79 & 24.23 & 58 & 17.8 & 42 & 12.9 & 49 & 15 & 326 & 100 \\
\hline & & & i-Squ & $=5.207$ & Value & 022 & & & & & & \\
\hline
\end{tabular}

Table 7: Distribution of percentage of pregnant women according to the degree of depression in relation to availability of supportive person.

\begin{tabular}{|c|c|c|c|c|c|c|c|c|c|c|c|c|}
\hline \multirow{3}{*}{ Degree of Depression } & \multicolumn{12}{|c|}{ Presence of Supportive Person } \\
\hline & \multicolumn{2}{|c|}{ No one } & \multicolumn{2}{|c|}{ Mother } & \multicolumn{2}{|c|}{ Husband } & \multicolumn{2}{|c|}{ Friend } & \multicolumn{2}{|c|}{ Another } & \multicolumn{2}{|c|}{ Total } \\
\hline & No. & $\%$ & No. & $\%$ & No. & $\%$ & No. & $\%$ & No. & $\%$ & No. & $\%$ \\
\hline None & 11 & 42.3 & 54 & 40.3 & 60 & 45.5 & 1 & 6.7 & 6 & 31.6 & 132 & 40.5 \\
\hline Mild & 9 & 34.6 & 51 & 38.1 & 38 & 28.8 & 5 & 33.3 & 8 & 42.1 & 111 & 34 \\
\hline Moderate & 3 & 11.5 & 19 & 14.2 & 24 & 18.2 & 6 & 40 & 4 & 21.1 & 56 & 17.2 \\
\hline Moderate to Severe & 1 & 3.8 & 8 & 6 & 8 & 6.1 & 3 & 20 & 0 & 0 & 20 & 6.1 \\
\hline Severe & 2 & 7.7 & 2 & 1.5 & 2 & 1.5 & 0 & 0 & 1 & 5.3 & 7 & 2.1 \\
\hline Total & 26 & 7.9 & 134 & 41.2 & 132 & 40.4 & 15 & 4.6 & 19 & 5.8 & 326 & 100 \\
\hline & & & Chi-Sq & 24.997 & lue $=0$ & & & & & & & \\
\hline
\end{tabular}


Table 8: Distribution of percentage of pregnant women according to the degree of depression in relation to exposure of violence by husband.

\begin{tabular}{|c|c|c|c|c|c|c|c|c|c|c|c|c|c|c|}
\hline $\begin{array}{l}\text { Exposure to } \\
\text { Violence by }\end{array}$ & & \multicolumn{12}{|c|}{ Degree of Depression } & \multirow{3}{*}{$\begin{array}{c}\text { Chi-Square } \\
\\
4.018\end{array}$} \\
\hline & \multicolumn{2}{|c|}{ None } & \multicolumn{2}{|c|}{ Mild } & \multicolumn{2}{|c|}{ Moderate } & \multirow{2}{*}{$\begin{array}{c}\text { Moderate } \\
\text { to Severe } \\
\%\end{array}$} & \multirow[b]{2}{*}{ No. } & \multicolumn{2}{|c|}{ Severe } & \multicolumn{2}{|c|}{ Total } & \multirow{2}{*}{$\begin{array}{c}\text { P-Value } \\
\%\end{array}$} & \\
\hline \multirow{4}{*}{ Physical } & & No. & $\%$ & No. & $\%$ & No. & & & $\%$ & No. & $\%$ & No. & & \\
\hline & Yes & 8 & 38.1 & 6 & 28.6 & 6 & 28.6 & 0 & 0 & 1 & 4.8 & 21 & 100 & \multirow{3}{*}{0.404} \\
\hline & No & 124 & 40.7 & 105 & 34.4 & 50 & 16.4 & 20 & 6.6 & 6 & 2 & 305 & 100 & \\
\hline & Total & 132 & 40.5 & 111 & 34 & 56 & 17.2 & 20 & 6.1 & 7 & 2.1 & 326 & 100 & \\
\hline \multirow{3}{*}{ Emotional } & Yes & 20 & 35.7 & 18 & 32.1 & 14 & 25 & 3 & 5.4 & 1 & 1.8 & 56 & 100 & \multirow{3}{*}{2.9690 .563} \\
\hline & No & 112 & 41.5 & 93 & 34.4 & 42 & 15.6 & 17 & 6.3 & 6 & 2.2 & 270 & 100 & \\
\hline & Total & 132 & 40.5 & 111 & 34 & 56 & 17.2 & 20 & 6.1 & 7 & 2.1 & 326 & 100 & \\
\hline \multirow{3}{*}{ Sexual } & Yes & 1 & 14.3 & 2 & 28.6 & 4 & 57.1 & 0 & 0 & 0 & 0 & 7 & 100 & \multirow{3}{*}{ 8. 5200.074} \\
\hline & No & 131 & 41.1 & 109 & 34.2 & 52 & 16.3 & 20 & 6.3 & 7 & 2.2 & 319 & 100 & \\
\hline & Total & 132 & 40.5 & 111 & 34 & 56 & 17.2 & 20 & 6.1 & 7 & 2.1 & 326 & 100 & \\
\hline
\end{tabular}

\section{Discussion}

The results (Table 2) indicated that one-third of the participants were exposed to at least one type of violence during the current pregnancy. Less than five percent $(2.1 \%)$ reporting sexual abuse and 6.4\% experienced physical violence and less than one fifth $(17.2 \%)$ reported emotional violence. These results were in line with results of a study conducted by WHO on women's health and domestic violence against women which revealed that the prevalence rate of physical violence by intimate partner during pregnancy ranged between $1 \%$ in a Japanese city to $28 \%$ in a Peruvian province, and ranged between $4 \%-12 \%$ in the other sites of study [9]. An analysis of the Demographic and Health Surveys and the International Violence [10] revealed that the intimate partner violence during pregnancy ranges between $2 \%$ in Australia, Denmark, Cambodia, and the Philippines to $13.5 \%$ in Uganda. Other global clinical studies reported that the most frequent occurrence of violence was in Egypt 32\%, followed by India 28\%, Saudi Arabia 21\% and Mexico 11\% [11]. Another review of clinical studies from Africa Shamu et al, [12] indicated that the prevalence rates of physical violence were $23-40 \%$ and the rate of sexual abuse was $3-27 \%$ and ranged between $25-49 \%$ for emotional violence by an intimate partner in the antenatal stage. Moreover, Thanaanowan [13] found that intimate partner violence during pregnancy was linked to detrimental health outcomes and fatalities in some cases for the pregnant woman and her baby due to the direct strain of abuse on a woman's body.

The findings (Table 3) indicated that nearly two-thirds of pregnant women $(59.5 \%)$ have depression symptoms in various degrees. Around one-third of pregnant women (34\%) and less than one fifth $(17.2 \%)$ reported mild and moderate symptoms of depression respectively. Similar results were reported by Songul [14] who found that $34.59 \%, 13.91 \%$ and $4.89 \%$ of the participants reported, mild, moderate, severe levels of depression. Other studies indicated to high rate of depression among women in different countries, it reached up to $39.5 \%$ in Tanzania [15], (39 $\%$ ) in two Cape Town peri-urban settlements [16], and reached $56 \%$ in Jamaica [17], while a relatively low rate was reported in Brazil (20.2 \%) [18] and in rural Bangladesh (18 \%) [19]. These differences in the prevalence rate of antenatal depression among countries might be due to socio-cultural differences as education level, economic status, religion, norms, and the availability of a supportive system. The findings (Table 4) revealed that more than half $(53.4 \%)$ of pregnant women in the age group 16-21 were classified to have no depression and $1.7 \%$ of them have severed degree of depression. 8.6\%,19.9\%,14.3\%,25\% and $33.3 \%$ of those who classified to have moderate degree of depression were from the age groups (16-21), (22-27), (28-33), (34-39), and $\geq 40$ years old respectively above with statistically significant differences (P-value, 0.017). According to Weissman (1995) [20], depressive symptoms are most often seen between 20 and 40 years old, the age range when many women become pregnant. Depression in an older woman is more likely due to diseases such as hypertension or diabetes mellitus. The results (Table 5) showed that the number of children is highly associated with depression as $5.2 \%$ and $12.1 \%$ of pregnant women who have 3 gravidities had a severe degree and moderate to severe degree of depression respectively. It also revealed that $33.7 \%, 35.4 \%, 34.5 \%, 31 \%$ and 34.7 of those who classified having a mild degree of depression were having 1, 2, 3,4 gravidities respectively with statistically significant differences between the degree of depression and number of children (P-value $=0.022<0.05)$. These results were incoherent with 


\section{Global Journal of Reproductive Medicine}

Lancaster el (2010) [21] who indicated that one of the greatest risk factors for depression in pregnancy was a higher number of existing children

The results (Table 6) indicate that lower depression among women who are supported either by their mothers or their hatbands than those who supported by friends or other relatives but without statistically significant differences (P-value $0.070>0.05)$. The results indicated that the pregnant women who have no degree of depression reported that (40.3\%) and (45.5\%) of them their support person was either their mother or hatbands respectively. It also indicated that $2.1 \%$ of pregnant women, who have a severe degree of depression, reported that either having no supportive person $(7.7 \%)$ or having another relative rather than a mother or husband (5.3\%). The previous studies indicated that found that lack of support is a risk factor for stress during pregnancy and it has it effects on pregnancy outcomes [22]. In addition, social support and visiting interventions have successful outcomes in improving the mental health of depressed mothers [23]. In Palestinian culture, the availability of a supportive person is highly appreciated by family members and it's from cultural perspectives to have either the mother or mother in law in addition to the husband as a supportive person especially when they are living in the same area. Sometimes it may lead to stress for pregnant women if it reaches to overprotection as providing more food and rest.

The results (Table 7) discussed the different types of violence in relation to degree of depression .it indicated that $4.8 \%$ of pregnant women who had severe depression, $28.6 \%$, and $28.6 \%$ of those who have a moderate and mild degree of depression respectively have been exposed to physical violence by their husband without significant differences (P-value=0.404). The same was found by Cohen [24], who found that physical violence affects pregnant women and it increases the likelihood of experiencing symptoms of depression and it also affects the infant's externalization behavior. In addition, Campbell [11] found that violence during pregnancy is frequent and it negatively affects both the woman's physical and mental health. In relation to emotional violence, the findings (Table 7) also indicated that $35.7 \%$ of pregnant women who had no degree of depression reported exposure to emotional violence by their husband, and $32.1 \%$ of those who had a mild degree of depression reported having been exposed to violence from their husband without significant differences. These findings were in the same line as Lancaster \& King [21,25] who indicated that intimate partner male violence was associated with symptoms of depression affect women. Regarding sexual violence, the result (Table 7) indicated that that $57.1 \%$ of those who have a moderate degree of depression were exposed to sexual violence by their husband while $2.2 \%$ of those who had severe depression have not been exposed sexual violence with no significant differences between them (P-value $=0.074)$. The same was revealed by Bailey
[26], who found that $10 \%$ of violence against women in the world was sexual in nature and had an effect on mental health and behavioral tendencies.

\section{Conclusion}

Pregnant women are more likely to get sign and symptom of depression when she has higher number of children and pregnancies. Exposure of pregnant women to Violence in all its types by her husband's is more likely to lead to different degree of depression. Availability of supportive person especially when he is the husband or mother is helping in Minimizing the degree of depression

\section{Recommendation}

a. Develop or adopting a depression assessment tool that to be used for detection of sign and symptoms of depression during antenatal period.

b. Ensuring availability of supportive person for pregnant especially for those who have no supportive once.

c. Further studies about antenatal depression among pregnant women in more details using the qualitative method.

Adopt policy and tool to detect the intimate partner violence, and to provide protection for those women who exposed to this type of violence

\section{References}

1. https://www.who.int/mental_health/management/depression/en/

2. Marcus M, Taghi Yasamy M, Ommeren M, Chisholm D, Saxena S (2012) WHO Department of Mental Health and Substance Abuse, Depression A Global Public Health Concern.

3. Wang J, Wu X, Lai W, Long E, Zhang X, et al. (2017) Prevalence of depression and depressive symptoms among outpatients: A systematic review and meta-analysis. BMJ Open 7(8): 1-14.

4. Talarowska M, Florkowski A, Zboralsk IK, Galecki PPsychiatr P (2010) Differences in the course of depressive disorders among women and men measured by MMPI-2. Psychiatr Pol 44(3): 319-328.

5. Albert PR (2015) Why is depression more prevalent in women? J Psychiatry Neurosci 40(4): 219-221.

6. Al Azri M, Al Lawati I, Al Kamyani R, Al Kiyumi M, Al Rawahi A, et al. (2016) Prevalence and Risk Factors of Antenatal Depression among Omani Women in a Primary Care Setting: Cross-sectional study. Sultan Qaboos University Medical Journal 16(1): e35-41.

7. Ajinkaya S, Jadhav P, Srivastava N (2013) Depression during pregnancy: Prevalence and obstetric risk factors among pregnant women attending a tertiary care hospital in Navi Mumbai. Ind Psychiatry J 22(1): 37-40.

8. Spitzer RL, Kroenke K, Williams JB (1999) Validation and utility of a self-report version of PRIME-MD: the PHQ primary care study. Primary Care Evaluation of Mental Disorders. Patient Health Questionnaire. JAMA 282(18): 1737-1744.

9. Bansil P, Kuklina EV, Meikle SF, Posner SF, Kourtis AP, et al. (2010) Maternal and fetal outcomes among women with depression. J Womens Health 19(2): 329-334. 
10. Devries KM, Kishor S, Johnson H, Stöckl H, Bacchus LJ, et al. (2010) Intimate partner violence during pregnancy: analysis of prevalence data from 19 countries. Reproductive Health Matters 18(36): 158-170.

11. Campbell J, García Moreno C, Sharps P (2004) Abuse during Pregnancy in Industrialized and Developing Countries. Violence Against Women 10(7): 770-789.

12. Shamu S, Abrahams N, Temmerman M, Musekiwa A, Zarowsky C (2011) A Systematic Review of African Studies on Intimate Partner Violence against Pregnant Women: Prevalence and Risk Factors. PLoS ONE 6(3): e17591.

13. Thananowan N, Heidrich SM (2008) Intimate Partner Violence Among Pregnant Women. Violence Against Women 14(5): 509-527.

14. Songul A, Kiymet C (2015) Factors Affecting Depression during Pregnancy and the Correlation between Social Support and Pregnancy Depression. Iran Red Crescent Med J 17(9): e16640.

15. Faisal Cury A, Menezes P, Araya R, Zugaib M (2009) Common mental disorders during pregnancy: prevalence and associated factors among low-income women in São Paulo, Brazil: depression and anxiety during pregnancy. Archives of Womens Mental Health 12(5): 335-343.

16. Hartley M, Tomlinson M, Greco E, Comulada WS, Stewart J, et al. (2011) Depressed mood in pregnancy: Prevalence and correlates in two Cape Town peri-urban settlements. Reproductive Health 8(1): 9.

17. Wissart J, Parshad O, Kulkarni S (2005) Prevalence of pre- and postpartum depression in Jamaican women. BMC Pregnancy and Childbirth 5(1): 15.

18. Manikkam L, Burns JK (2012) Antenatal depression and its risk factors: An urban prevalence study in KwaZulu-Natal. South African Medical Journal 102(12): 940-944.
19. Nasreen HE, Kabir ZN, Forsell Y, Edhborg M (2011) Prevalence and associated factors of depressive and anxiety symptoms during pregnancy: A population based study in rural Bangladesh. BMC Womens Health 11(1): 22.

20. Weissman M, Olfson M (1995) Depression in women: implications for health care research. Science 269(5225): 799-801.

21. Lancaster CA, Gold KJ, Flynn HA, Yoo H, Marcus SM, et al. (2010) Risk factors for depressive symptoms during pregnancy: a systematic review. American Journal of Obstetrics and Gynecology 202(1): 5-14.

22. Elsenbruch S, Benson S, Rucke M, Rose M, Dudenhausen J, et al. (2006) Social support during pregnancy: effects on maternal depressive symptoms, smoking and pregnancy outcome. Human Reproduction 22(3): 869-877.

23. Holden JM, Sagovsky, R Cox JL (1989) Counseling in a general practice setting: controlled study of health visitor intervention in treatment of postnatal depression. BMJ 298(6668): 223-226.

24. Cohen LS, Altshuler LL, Harlow BL (2006) Relapse of Major Depression During Pregnancy in Women Who Maintain or Discontinue Antidepressant Treatment. JAMA 296(5): 499-507.

25. Kring AM, Persons JB, Thomas C (2010) Changes in affect during treatment for depression and anxiety. Behaviour Research and Therapy 45(8): $1753-1764$.

26. Bailey BA (2010) Partner violence during pregnancy: prevalence, effects, screening, and management.

Your next submission with Juniper Publishers
will reach you the below assets
- Quality Editorial service
- Swift Peer Review
- Reprints availability
- E-prints Service
- Manuscript Podcast for convenient understanding
- Global attainment for your research
- Manuscript accessibility in different formats
( Pdf, E-pub, Full Text, Audio)
- Unceasing customer service
Track the below URL for one-step submission
https://juniperpublishers.com/online-submission.php

